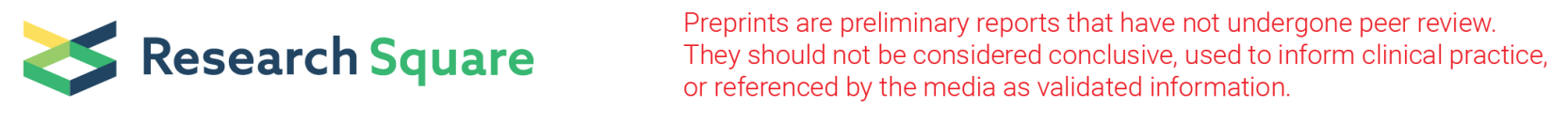

\title{
Development and Operationalization of a Data Framework to Assess Quality of Integrated Diabetes Care in the Fragmented Data Landscape of Belgium
}

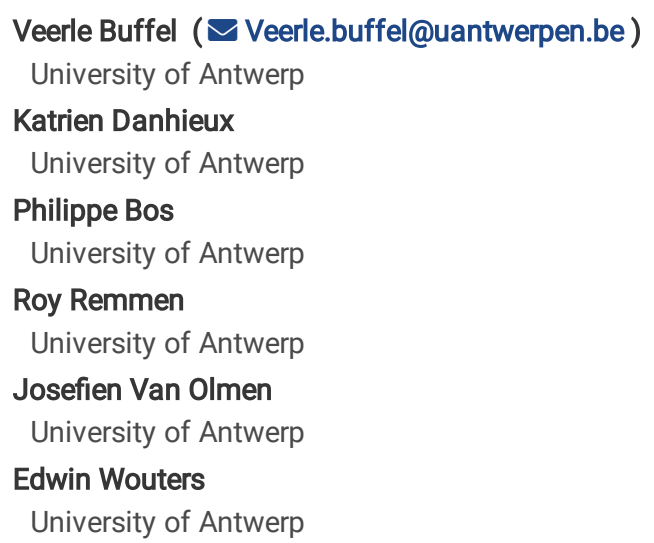

Keywords: Primary care, Routinely Collected Data, Quality of Healthcare, Type 2 Diabetes, Integrated Delivery Systems

Posted Date: January 6th, 2022

DOI: https://doi.org/10.21203/rs.3.rs-1173627/v1

License: (c) (i) This work is licensed under a Creative Commons Attribution 4.0 International License. Read Full License 


\section{Abstract}

Background. To assess the quality of integrated diabetes care, we should be able to follow the patient throughout the care path, monitor his/her care process and link them to his/her health outcomes, while simultaneously link this information to the primary care system and its performance on the structure and organization related quality indicators. However the development process of such a data framework is challenging, even in period of increasing and improving health data storage and management. This study aims to develop an integrated multi-level data framework for quality of diabetes care and to operationalize this framework in the fragmented Belgium health care and data landscape.

Methods. Based on document reviews and iterative expert consultations, theoretical approaches and quality indicators were identified and assessed. After mapping and assessing the validity of existing health information systems and available data sources through expert consultations, the theoretical framework was translated in a data framework with measurable quality indicators. The construction of the data base included sampling procedures, data-collection, and several technical and privacy-related aspects of linking and accessing Belgian datasets.

Results. To address three dimensions of quality of care, we integrated the chronic care model and cascade of care approach, addressing respectively the structure related quality indicators and the process and outcome related indicators. The corresponding data framework is based on self-collected data at the primary care practice level (using the Assessment of quality of integrated care tool), and linked health insurance data with lab data at the patient level.

Conclusion. In this study, we have described the transition of a theoretical quality of care framework to a unique multilevel database, which allows assessing the quality of diabetes care, by considering the complete care continuum (process and outcomes) as well as organizational characteristics of primary care practices.

\section{Background}

Type 2 Diabetes (T2D) is one of the leading causes of death in the world with 3.7 million deaths/year [1]. In Belgium, $6.1 \%$ of the population is diagnosed with diabetes [2]. Effective interventions for prevention and control are available and are relatively straightforward from a technical point of view. However, T2D care is socially and organizationally complex. It requires lifelong follow-up and self-management along a continuum of care: patients need to be diagnosed, treated, followed-up, and supported to achieve glycemic control. Unfortunately, a substantial amount of people are lost at each of these steps, leading to sub-optimal uptake of high-quality care [3]. These gaps in the continuum of care are related to both demand (patient) and supply (healthcare organization) side characteristics. At the demand side, research has indicated that people living in socio-economically vulnerable conditions are significantly more likely to be lost alongside the continuum of care [3]. This contributes to the growth of health inequalities that health systems were designed to address but failed to do [4]. At the supply side, differences exist between providers how they treat their patients and how they organize their practices, especially in primary care, where the biggest volume of T2D patients is treated $[5,6]$. Therefore, assessing the quality of T2D care and investigating differences in this quality between patient groups and different types of primary care practices are highly relevant.

Following Donabedian's landmark model [7-10], quality of care has three dimensions: 1) structure; 2) process; and 3) outcomes. The first dimension [7] is about how care is organized. It refers to the elements that form the basis of the healthcare system, including the accessibility of care facilities [24, 25], an adequate mix of human resources [11], up-to-date equipment [12], a well-working health information system (HIS), and integrated policies. The second dimension addresses the questions on the medical interaction (at a technical and interpersonal level). It refers to the completeness, continuity, and functional quality of activities for diagnosis and treatment. The third dimension covers the intermediate health outcomes and/or the end results of the healthcare or intervention. These are rather indirectly related to the care provider's actions and the organization of care, and are much more influenced by other factors such as patient characteristics and the environmental context [28]. These three dimensions are especially relevant for the quality of chronic care, such as diabetes care $[5,13,14]$.

In order to get a comprehensive overview of the multidimensional quality of care for a chronic disease such as T2D, one needs complex data -i.e. data on structure, process and outcome of a continuum of care. Ideally one should follow the patient (demand side) along this care continuum to assess the process and outcomes of primary healthcare. In addition, information on the organization of healthcare (supply side) is required to assess the performance of structure related quality indicators (QI).

Although there is a proliferation of individual health information registration and storage, the linkage of the three QIs remains challenging, also in welldeveloped healthcare systems. Until now, it has only been done at a small scale (in a few health centers, hospitals or intentionally collected for a study project $[11,15])$ and at aggregated levels making at it impossible to study quality differences between patient groups and primary care organizations, or in countries with a very well-structured HIS, for example where a comprehensive diabetes register is available [16] (such as in Sweden [17], the UK [18], Denmark [19], and Toronto [20]).

Especially in fragmented healthcare systems with a similar complex health data landscape, the development process of such a data framework is constrained by conceptual, organizational, technical, and legal barriers. Conceptually, a standardized language of patient health information registration (electronic health records (EHRs)) is still lacking between different registration systems and health services. At the organizational level, these EHRs are often not stored or made accessible at a central database or platform and need to be manually extracted and collected. Or they are 
only provided at the aggregated level (e.g. primary care practice level, regional level), which may led to wrong interpretations of observed quality differences, hiding differences in patients' needs. As alternative to EHRs, several studies rely on health insurance data. In these data, however, outcome related quality information is mostly lacking, as the majority of clinical outcomes are rarely registered for administrative purposes. Many information is thus stored but in a fragmented way without an overall vision, such that discussions on monitoring datasets are preceded by discussions about the relevance, priority, feasibility and validity of the data included in such datasets [21]. This then results in technical, legal and ethical challenges when researchers attempt to get access to the data and to link the datasets (e.g. data matching procedures, data protection issues, etc.) [22].

In this study, we aim to address these challenges by developing and operationalizing a multilevel data framework for the quality of T2D care, in the context of a highly fragmented health system without a national diabetes register [16], as is the case in Belgium. The study addresses the following research questions: 1) How do we measure the structure, process and outcomes of integrated diabetes care?; 2) Which data sources are available and what are their strengths and limitations?; and 3) How do we design and operationalize an integrated diabetes care database, allowing quality assessment and the analysis of differences in quality between patients groups and primary care practices.

\section{Methods}

\section{Study setting}

This study is part of a larger research project SCUBY 'SCale-UP Diabetes and hYpertension care in Belgium, Cambodia and Slovenia' [23]. The current study is approved by the Ethical Committee of the University Hospital Antwerp (ref.20/06/069) and all methods were performed in accordance with the relevant guidelines and regulations (Declarations of Helsinki). In Belgium, healthcare providers and patients enjoy a high degree of autonomy in their choice of service utilization and care provider, which has led to a fragmented system of individualized care [24, 25]. Patients are not obliged to register at one General Practitioner (GP) and GPs can choose their financing system (fee-for-service (FFS) or capitation) and how they organize their practice (solo versus group, multi- versus monodisciplinary).

This complexity and high degree of autonomy is also reflected in the Belgian HIS and data landscape. At the primary care level, various EHR systems co-exist and the major aim of these systems is to facilitate medical record-keeping for the GP. Health care professionals only share limited information with each other and the exportation of EHR data to administration or quality control institutions is no routine. A recent development is the incentivization for adequate registration [22] of a limited number of indicators, such as the percentage of people in a diabetes care trajectory or the number of COVID diagnoses [26]. (Further developments in the Belgian HIS can be found in S1).

\section{Study design}

We used a case study approach by focusing on chronic care for T2D patients, but the proposed methodology and the development of the measurement and multilevel data framework can also be relevant for the assessment of the quality of chronic care in general or other specific types of chronic care. We relied on a phased approach (presented in Figure 1): phase 1) development of a measurement framework for quality of care; 2) mapping of relevant health data sources; 3) designing the data framework, 4) construction of the dataset and 5) formulating research questions and building the corresponding analysis models for the dataset. The methods used through these phases were document review and expert consultation rounds.

\section{Results}

\section{Phase 1: Development of a measurement framework for quality of care}

As Donabedian prescribed [7], indicators on organization, process and outcome are needed. For quality indicators related to the organization of care, we relied on the chronic care model (CCM). The literature review pointed to the CCM as the most frequently used standard for the organisation of chronic care at the primary care level. It identifies six key health system elements in improving primary care for chronic diseases to be optimized: the healthcare organization, delivery system design, clinical information systems, decision support, self-management support, and community resource linkages [27]. There is growing evidence showing that primary care organisations that implement CCM produces better outcomes for T2D patients [28]. The degree of successful implementation of the CCM is evaluated by the Assessment of Chronic Illness Care tool (ACIC) [29, 30].

Chronic care cannot be captured by a single outcome measure as it entails, by definition, continuous illness management, drawing the attention to both process and outcome indicators. In order to be able to comprehensively measure the chronic disease process and outcomes, a standardized measurement tool of the entire disease continuum thus needs to be developed - one which incorporate all steps of T2D management and outcomes [31, 32]. The document review guided the expert group towards a model known as the cascade of care (CoC). The CoC is a model that outlines the sequential steps in long-term care (prevalence, screening, diagnosis, linkage with care, in treatment, under control). CoC research has helped quantify losses of patients from care (so-called leakages), identify the points of greatest attrition, and target interventions to address these losses [33]. Most studies relying on a CoC approach are on HIV care [33]. However, recently some studies emerged that have shown its relevance for diabetes care. However these are mainly performed outside Europe -in the US [31], India [34], and South and sub-Saharan Africa [32, 35]- which 
stressed the need for studies in Belgium or other Western European countries which are so far lacking. The CoC was tested among the expert groups and appreciated as a feasible and useful tool to measure T2D outcomes in Belgium (Flanders)[36].

The integration of both, the 'CCM' and the 'CoC', within the Structure-Process-Outcome paradigm is presented in Table 1 together with the quality dimensions, corresponding measurable indicators and data level.

Table 1

Dimensions of quality of care addressed by the integration of the chronic care model and cascade of care

\begin{tabular}{|c|c|c|c|}
\hline $\begin{array}{l}\text { Dimension of quality of care } \\
\text { (cfr. Donedian's model) }\end{array}$ & Theoretical approach & Measuring tool & Data level \\
\hline Structure and organization & Chronic care model & $\begin{array}{l}\text { ACIC-Sub scores: } \\
\text {-Organization } \\
\text {-Community linkages } \\
\text {-Self-management support } \\
\text {-Decision support } \\
\text {-Delivery system design } \\
\text {-Information systems }\end{array}$ & $\begin{array}{l}\text {-Health system } \\
\text {-Primary care practice }\end{array}$ \\
\hline Process & Cascade of care approach & $\begin{array}{l}\text { CoC bars: } \\
\text {-tested } \\
\text {-diagnosed } \\
\text {-linked to care } \\
\text {-taking treatment } \\
\text {-followed up, }\end{array}$ & $\begin{array}{l}\text {-Patient } \\
\text { (individual level) }\end{array}$ \\
\hline Outcomes & & -under control & \\
\hline
\end{tabular}

\section{Phase 2: Mapping of relevant health data sources}

A mapping exercise was done to assess the different health data sources in order to see whether all data required to measure quality of integrated T2D care are available. The strengths and limitations of the data and options to connect the data with other data sources were evaluated. The results of this exercise are summarized in Table 2.

Table 2: Results of the assessment of the existing health data sources for T2D care

\section{Phase 3: Designing the data framework}

\section{Selection of data sources}

As structure related quality data in primary care practices are not systematically available in Belgium, this data is self-collected at the primary care practice level. For the actual construction of the database, we start therefore with the selection of GP-practices and their patient populations (see phase 4).

A recent Belgian study has shown that for T2D a purely administrative database was the most reliable source to estimate disease prevalence based on dispensed medication in comparison to prescribed or self-reported medication data [37]. Although the quality of registration by GPs shows a 


\begin{tabular}{|c|c|c|c|c|c|c|}
\hline Type & $\begin{array}{l}\text { Collected/owned by } \\
\text { (part of project) }\end{array}$ & Period & $\begin{array}{l}\text { Population } \\
\text { (representativeness) }\end{array}$ & Content & Strengths & Limitations \\
\hline \multicolumn{7}{|c|}{ PATIENT SURVEY DATA } \\
\hline $\begin{array}{l}\text { Health } \\
\text { Interview } \\
\text { survey }(\mathrm{HIS})^{(1)}\end{array}$ & $\begin{array}{l}\text { Sciensano (Belgian } \\
\text { Institute for Health) }\end{array}$ & $\begin{array}{l}\text { Repeated } \\
\text { cross- } \\
\text { sectional: } \\
\text { every } 4 \text { years } \\
\text { since } 1997\end{array}$ & $\begin{array}{l}\text { Representative } \\
\text { sample of the } \\
\text { Belgian population } \\
\text { (N=+/-10000 } \\
\text { respondents) }\end{array}$ & $\begin{array}{l}\text { medication use, } \\
\text { health care use and } \\
\text { costs, health } \\
\text { behavior (physical } \\
\text { activity, diet, } \\
\text { smoking, alcohol), } \\
\text { BMI, diagnostic } \\
\text { information }\end{array}$ & $\begin{array}{l}\text {-Representative } \\
\text { for the population } \\
\text {-Extensive lifestyle } \\
\text { and } \\
\text { sociodemographic } \\
\text { info }\end{array}$ & $\begin{array}{l}\text {-Small numbers } \\
\text { of T2D patients } \\
(6,2 \%) \\
\text {-Self-reported } \\
\text { data, recall bias } \\
\text {-Selection and } \\
\text { sample bias } \\
\text {-The most } \\
\text { severe and } \\
\text { institutionalized } \\
\text { patients are } \\
\text { excluded } \\
\text {-Time lag: data } \\
\text { of } 2018 \text { was } \\
\text { available in } \\
2021 \\
\text {-Cross-sectional } \\
\text { data } \\
\text {-No clinical } \\
\text { data } \\
\text {-No information } \\
\text { about type of } \\
\text { GP-practice }\end{array}$ \\
\hline $\begin{array}{l}\text { Belgian Health } \\
\text { Examination } \\
\text { study } \\
\text { (BELHES) }^{(2)}\end{array}$ & & $\begin{array}{l}\text { Cross- } \\
\text { sectional: } \\
2018\end{array}$ & $\begin{array}{l}\text { Representative } \\
\text { subsample of the } \\
\text { HIS }(\mathrm{N}=+/ 1200 \\
\text { respondents) }\end{array}$ & $\begin{array}{l}\text { blood and urine } \\
\text { test, blood pressure } \\
\text { measure, BMI }\end{array}$ & $\begin{array}{l}\text {-Clinical data } \\
\text {-Can be linked to } \\
\text { HIS data }\end{array}$ & $\begin{array}{l}\text {-Small sample } \\
\text { (+ same } \\
\text { limitations HIS } \\
\text { data) }\end{array}$ \\
\hline \multicolumn{7}{|c|}{ HEALTH PROFESSIONAL SURVEY DATA } \\
\hline $\begin{array}{l}\text { Sentinel } \\
\text { Network of } \\
\text { General } \\
\text { Practitioners } \\
\text { (surveillance } \\
\text { network) }\end{array}$ & $\begin{array}{l}\text { A network of } \\
\text { Registered GPs, } \\
\text { coordinated by } \\
\text { Sciensano }\end{array}$ & $\begin{array}{l}\text { Longitudinal: } \\
\text { since } 1979 \\
\text { Periodic } \\
\text { modules to } \\
\text { monitor one } \\
\text { or more } \\
\text { specific } \\
\text { illness } \\
\text { problems }\end{array}$ & $\begin{array}{l}\text { A network of } 125 \\
\text { practices (their } \\
\text { patient population } \\
\text { covers } 1-1,5 \% \text { of the } \\
\text { Belgian population) }\end{array}$ & $\begin{array}{l}\text { sociodemographics, } \\
\text { treatment and } \\
\text { morbidity data }\end{array}$ & $\begin{array}{l}\text {-Representative } \\
\text { for Belgian GP } \\
\text { workforce } \\
\text {-Able to study the } \\
\text { evolution and } \\
\text { epidemiology of } \\
\text { certain diseases }\end{array}$ & $\begin{array}{l}\text {-Quality of data } \\
\text { strongly } \\
\text { depends on the } \\
\text { reporting } \\
\text { quality of GPs } \\
\text {-The most } \\
\text { recent T2D } \\
\text { module was in } \\
2010\end{array}$ \\
\hline \multicolumn{7}{|l|}{ REGISTER DATA } \\
\hline $\begin{array}{l}\text { Belgian } \\
\text { Diabetes } \\
\text { Register }^{(4)}\end{array}$ & Diabetes Liga & $\begin{array}{l}\text { Longitudinal: } \\
\text { since } 1997\end{array}$ & $\begin{array}{l}\text { New patients }<40 \\
\text { years old diagnosed } \\
\text { with T1D }\end{array}$ & $\begin{array}{l}\text { sociodemographics, } \\
\text { clinical data }\end{array}$ & $\begin{array}{l}\text {-Clinical data } \\
\text {-Longitudinal }\end{array}$ & $\begin{array}{l}\text {-Only T1D } \\
\text { patients (not } \\
\text { the target } \\
\text { population of } \\
\text { this study) }\end{array}$ \\
\hline $\begin{array}{l}\text { IQED: Initiative } \\
\text { for Quality } \\
\text { Improvement \& } \\
\text { Epidemiology } \\
\text { in Diabetes }{ }^{(5)}\end{array}$ & $\begin{array}{l}\text { Hospital based data } \\
\text { requested by } \\
\text { Sciensano for audit } \\
\text { (Surveillance of the } \\
\text { convention for } \\
\text { diabetes self- } \\
\text { regulation) }\end{array}$ & $\begin{array}{l}\text { Repeated } \\
\text { cross- } \\
\text { sectional } \\
\text { retrospective } \\
\text { study design } \\
\text { (every } 18 \\
\text { months): } \\
\text { since } 2001\end{array}$ & $\begin{array}{l}\text { Patients in a } \\
\text { diabetes care } \\
\text { trajectory: }+/-100 \\
\text { diabetic centres } \\
\text { treated }+/-120000 \\
\text { patients } \\
\text {-each time } 10 \% \text { of } \\
\text { the population is } \\
\text { sampled }\end{array}$ & $\begin{array}{l}\text { clinical hospital } \\
\text { data, socio- } \\
\text { demographics, type } \\
\text { of diabetes and } \\
\text { complications, } \\
\text { diabetes treatment, } \\
\text { health examination } \\
\text { data }\end{array}$ & $\begin{array}{l}\text {-Clinical data } \\
\text {-Focus on quality } \\
\text { indicators }\end{array}$ & $\begin{array}{l}\text {-Only type } 1 \\
\text { and type } 2 \\
\text { diabetic } \\
\text { patients treated } \\
\text { with } 2 \text { or more } \\
\text { insulin } \\
\text { injections per } \\
\text { day (only a } \\
\text { small part of } \\
\text { the target } \\
\text { population of } \\
\text { this study) }\end{array}$ \\
\hline \multicolumn{7}{|c|}{ PATIENT RECORD DATA } \\
\hline Patients & $\begin{array}{l}\text { GPs in their } \\
\text { practices }\end{array}$ & Longitudinal: & $\begin{array}{l}\text { Patient-population } \\
\text { of GP }\end{array}$ & Depending on GP & $\begin{array}{l}\text {-Data can be very } \\
\text { comprehensive }\end{array}$ & $\begin{array}{l}\text {-Several } \\
\text { software }\end{array}$ \\
\hline
\end{tabular}




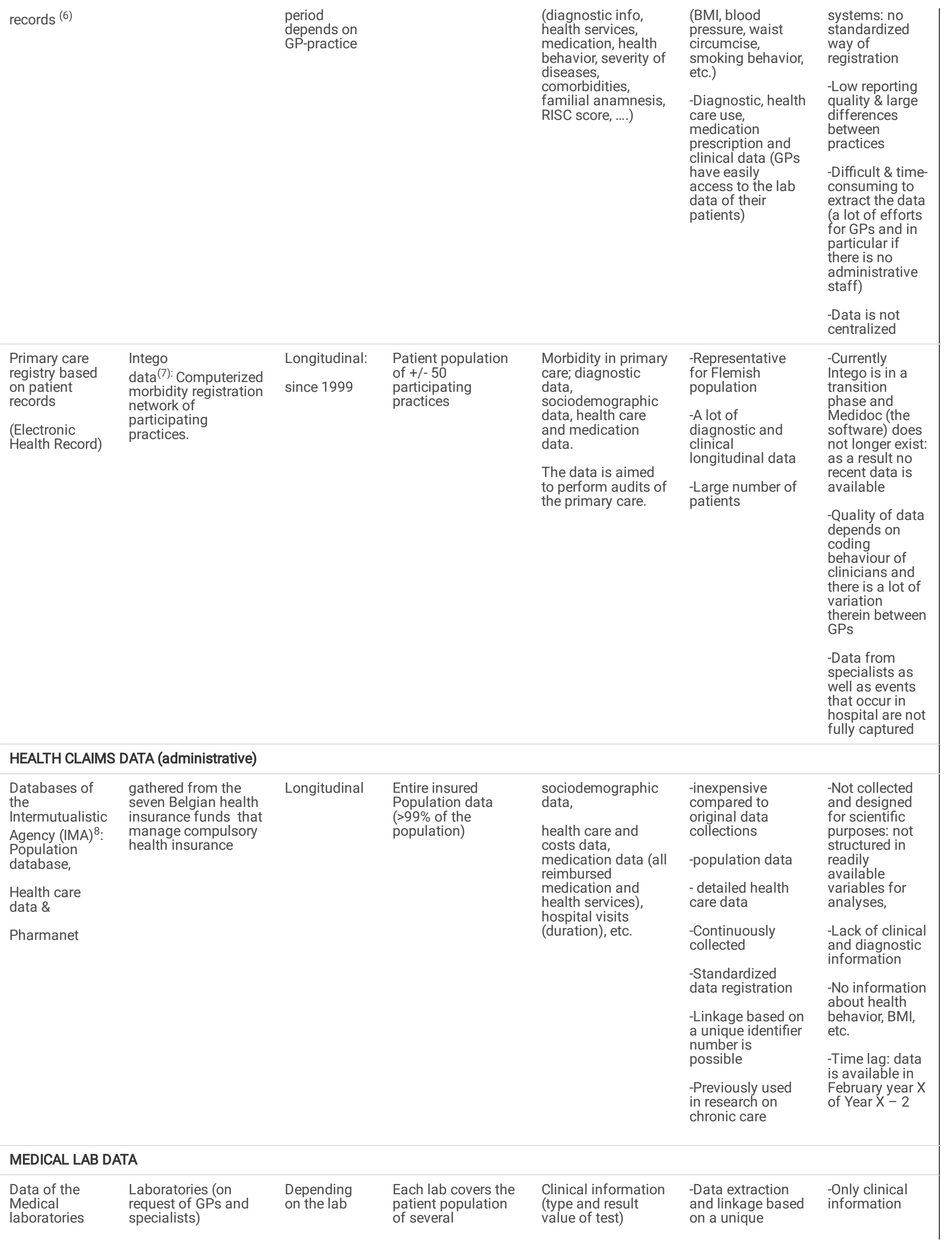

Page 6/15 
GPs/specialists/

hospitals identifier number

is possible

-Longitudinal data

-Comprehensive

clinical

information
$-+/-70$

accredited labs

-Several Lab information systems (LIS)

Sources: (1) https://www.sciensano.be/en/projects/health-interview-survey-2018; ${ }^{(2)}$ https://www.sciensano.be/en/projects/health-examinationsurvey, ${ }^{(3)}$ https://www.sciensano.be/en/network-general-practitioners ${ }^{(4)}$ https://www.diabetes.be/belgisch-diabetes-register;

${ }^{(5)}$ https://www.sciensano.be/en/projects/initiative-quality-improvement-and-epidemiology-

diabetes; ${ }^{(6)}$ https://www.ehealth.fgov.be/ehealthplatform/file/view/AWutmy6TnF_Mkwg-mMBj?filename=GP\%20documentation\%20-

8th\%20July\%20\%202019.pdf; (7) https://intego.be/nl/Welkom, ${ }^{(8)}{ }^{-h t t p s: / / i m a-a i m . b e /-O n z e-d a t a b a n k e n . ~}$

positive evolution, recent numbers however indicate that $30 \%$ of the patients is still missing in the registrations, and that also among the registered patients, crucial information - especially about clinical parameters- is lacking [38]. Therefore, and in the absence of an exhaustive register of T2D patients or a centralization and standardization of valid data of EHR in Belgium, we have opted for a combination of health insurance and lab data as this provides the necessary longitudinal and most valid and complete information at the patient level. Health insurance data is available through the Intermutualistic Agency (IMA), a platform where data gathered from the seven Belgian health insurance funds are collected. Medical lab data is until now not centralized, but distributed among more than 60 recognized laboratories active in Belgium.

\section{Selection and operationalization of quality measures}

The ACIC has been developed to evaluate chronic illness care [29] and was previously validated in Flanders [30, 31]. It is a comprehensive tool targeting generic organization of chronic care across disease populations, and attempts to represent poor to optimal organization and support of care in the CCM areas. In addition to the self-gathered information, information about the composition of the patient population of each GP-practice is retrieved from the IMA dataset (by aggregating patient information of this population (age and gender distribution, volume, caseload, etc.).

The $\mathrm{CoC}$, which integrates the process and outcome related indicators is operationalized by adapting the bars to the Belgian context and the available IMA and lab data (Table 3). The different bars can be calculated as percentages in general or per patient group or type of primary care practice.

\section{Table 3}

The operationalization of the Cascade-of-Care

\begin{tabular}{|c|c|c|c|c|}
\hline \multicolumn{2}{|c|}{ Stage of CoC } & \multirow{2}{*}{$\begin{array}{l}\text { Time (year) } \\
x-3-\text { to } x-1 \\
(2015-17)\end{array}$} & \multirow{2}{*}{$\begin{array}{l}\text { Operationalization } \\
\text { every } 3 \text { year a blood test on glucose/HbA1c*}\end{array}$} & \multirow{2}{*}{$\begin{array}{l}\text { Data } \\
\text { source }\end{array}$} \\
\hline 1 & Tested & & & \\
\hline 2 & Diagnosed & $x-1(2017)$ & proxies: T2D medication**/pre-diabetes pass & IMA \\
\hline 3 & In care & $\begin{array}{l}x-1 \text { to } x(2017- \\
18)\end{array}$ & >=3 GP-visits each year & IMA \\
\hline 4 & In treatment & $x(2018)$ & $>=2 \mathrm{HbA} 1 \mathrm{c}$ measurements each year & IMA \\
\hline 5 & $\begin{array}{l}\text { Follow up*** } \\
{[56]}\end{array}$ & $\begin{array}{l}x \text { to } x+1(2018- \\
19)\end{array}$ & $\begin{array}{l}>=2 \mathrm{HbA} 1 \mathrm{c} \text { measurements, } \\
\text { >= } 4 \text { glycaemia measurements, >= } 1 \text { lipid profile, >=1 microalbuminuria, >= } 1 \text { consultation by } \\
\text { an ophthalmologist }\end{array}$ & IMA \\
\hline 6 & $\begin{array}{l}\text { Under } \\
\text { control }\end{array}$ & $\mathrm{x}+1$ (2019) & $\mathrm{HbA} 1 \mathrm{c}<53 \mathrm{mmol} / \mathrm{mol}$ & Lab-data \\
\hline
\end{tabular}

\section{Phase 4: Construction of the dataset}

\section{4.a Selection of GP-practices and patients}

The sampling procedure is theoretically driven as it intends to collect a sample with optimal variation of primary care delivery models in order to link structure related quality information to process and outcome indicators. In Belgium (Flanders), primary care facilities can be categorized according to two dimensions, which are also highlighted as relevant health system factors in chronic care research [39]: financing (FFS vs. capitation) and organization (mono- vs. multidisciplinary). A GP-practice is considered as multidisciplinary, when it consists of one or more GPs and at least one nurse and/or dietician. We opted for these two disciplines in addition to the GP, as these play a prominent role in T2D management [40]. Based on these dimensions, four types of GP-practices can be distinguished in theory, but in practice, only three types actually exist in Belgium (Flanders) [41]: (a) 
monodisciplinary and FFS, (b) multidisciplinary and FFS, and (c) multidisciplinary and a capitation payment system in which patients subscribe for an annual fixed fee. Previous research [41, 42] has already confirmed the relevance of this categorization, showing for example that the control of hemoglobin A1c (HbA1c) and the prescription of statins was better in GP-practices with a fixed capitation system compared to FFS practices [41, 42].

In addition, we captured a range of socioeconomic factors and levels of urbanization, as research [35] has shown the importance of urbanization level in terms of care accessibility. In order to optimise the maximum mix of variability (also in terms of health systems), we opt for Antwerp, Ghent and Kempenland region.

Within each area, the GP-practices are categorized in the three primary care types. As the number of multidisciplinary practices is very low in Flanders, all multidisciplinary practices are selected in the three areas, while for the monodisciplinary practices, a random selection is performed in each area. This has resulted in 66 primary care facilities, which host 277 individual GPs (see S2).

The GPs have a unique identification code and IMA has developed a procedure to identify the patients population of each GP [43]. As patients have also a unique identification code, the linkage between the GP-practices and patient information is possible. Within the identified patient populations all T2D patients above 40 years old in year [ $\mathrm{x}-1]$ are selected. As IMA data lacks diagnostic information, patients diagnosed with T2D are algorithmically identified based on the proxies taking T2D medication (metformin, sulfonylurea, insulin) or having a pre-diabetes pass (registration in this care trajectory allows the reimbursement of a consult with a dietician, podiatrist and diabetes educator) in year [x-1] [44-46]. This algorithm is validated by medical experts and already used in other research [44-46]. Individual level data for this patient population for a period of three years (from year [ $\mathrm{x}-1]$ to year $[x+1)$, with year $[x+1]$ being the most recent available IMA data). Assuming approximately 641 patients per GP (mean in Flanders) and a conservative T2D prevalence of $6.1 \%$ (based on the Health Interview Survey of 2018 representative for the Belgian population), we will reach a final sample of at least 10.830 patients.

\section{4.b Collecting data at primary care level}

The quality of diabetes care is evaluated through structured interviews with observations of GPs and paramedics. Two researchers have scored the practices independently using the ACIC. During a discussion afterwards, a consensus score is defined per item. The six elements of the ACIC are separately assessed by 3 or more items, providing a subscale score: organization of the healthcare delivery system; community linkages; selfmanagement support for patients; decision support for service providers; delivery system redesign; and clinical information system (5 items). The overall ACIC score (an average of the six subscale scores) indicates optimal support for chronic illness.

\section{4.c Recruitment of medical labs}

During the interviews, the GPs were requested to provide the names of medical laboratories with whom they cooperate. This resulted in a list of seven laboratories active in primary care, which was completed with the labs of the hospitals in the study area, because diabetes patients can also be referred to one of these labs by a specialist or during a hospital stay. This bring us to 12 laboratories which may capture clinical data of the patient population of this study. All these laboratories are recognized by the Scientific Institute of Public Health and their contact information is publicly available.

We contacted the laboratories telephonically to explain the study, why they are a crucial partners in this project, and what we expect from them. Directly after this first contact, an email was send with more extended information, such as the concrete steps in the collaboration process, which kind of data we request, and a formed consent which they had to sign if they agreed on the collaboration.

\section{4.d Access and application procedures}

Three types of approval were needed for the construction of the database including IMA data and its linkage to the lab and self-collected data at the GP-practices: (1) approval from the relevant ethical commission; (2) internal approval from the database administrator organization and (3) approval from the information protection commission [47].

(1) We applied for the Ethics committee of Antwerp University Hospital, which advises on all ethical aspects in the context of scientific research.

(2) To obtain data and collaboration of the IMA a declaration of interest needed to be set up between researchers of the project and the IMA programme managers. The research proposal was discussed and after they agreed on collaboration, the project was in short presented to IMA registry directory board for approval. After this internal approval, a final detailed selection of the data and variables with the required motivation was prepared with the support of data managers of IMA.

(3) Thereafter approval was requested of the institution of social security and health, a subcommittee of the Information Protection Committee. The full process from application to approval can take six months and during this process additional information about the linkage procedure can be requested or a risk analysis to ensure privacy of the included individuals. 


\section{4.e Data trajectory and linkage procedure}

The data trajectory is developed in collaboration with IMA and has been submitted to eHealth in advance of the application for approval of the ethical commission and the information protection commission. A common unique identifier (i.e. social security number = INSZ or RIZIV) made deterministic linking possible. For privacy reasons, two trusted Third Parties (TTPs) 'eHealth' (a data platform of the federal government) and 'Crossroads Bank for Social Security' (CBSS) are responsible for this deterministic matching procedure using multiple encrypted social security numbers.

The linkage procedure consists of 13 steps (see flow chart and steps in S3) of data coding or decoding and data transfers (using the principle of random transport number 'RN') needed to ensure that none of the involved parties would have access to the sensitive data and the social security numbers. Only researchers of the project have access to the complete linked database without unique identifiers using a virtual private network (VPN).

\section{Phase 5: Formulating research questions and building the corresponding analysis models for the dataset}

The data will provide the opportunity to develop evaluation questions about the three dimensions of Donabedian's quality framework and the correlation between the dimensions structure, process and outcomes. To assess and visualize the Qls in a comprehensive way, two types of graphs will be constructed: the organization related indicators measured by the ACIC will be presented in a spiderweb [49] and the process and outcome indicators in a bar chart visualizing the $\mathrm{CoC}$ [33]. The spiderwebs linked to the CoCs can be stratified by health systems and/or patients groups to describe quality differences between the three GP-practice types and/or vulnerable and non-vulnerable patients (see a fictive example in Figure 2).

To further analyse which factors (e.g. socioeconomic status of the patient, gender, age) are related to the drops in the cascade, the drops will be used as dichotomous outcome variables of bivariate and multivariable logistic regression analyses. Knowledge on these leakages will inform healthcare reforms targeting those T2D patients currently not tested, undiagnosed, unlinked to care, not taking treatment, poor followed-up, and not achieving glycemic control.

By combining the patient level data with the GP-practice data, we will be able to explain observed differences in process and outcome related quality measures between GP-practices by the degree of successful implementation of the CCM. The multilevel structure of the data - patients (level 1) clustered within GP-practices (level 2) (see figure in S4) - will allow for multilevel analyses to estimate the impact of structure related factors (GPpractice level) on patients' probabilities of reaching (or not reaching) a particular stage in the cascade.

\section{Discussion And Conclusion}

This study has developed a unique multilevel data framework for assessing the quality of integrated T2D care and operationalized this framework in the fragmented Belgium healthcare and data landscape. The integration of (1) the Structure-Process-Outcome model of Donabedian with (2) a CoC approach enables us to not only assess the quality of care via the different dimensions, but to also investigate and understand differences in the quality of care and the impact of organization related factors on the total care continuum instead of only patient outcomes [48]. The clustering of patients in primary care practices and the availability of data at both levels enables us to relate differences in the quality of care between patient groups and types of GP-practices to organizational factors of the primary care practices and the extent of the implementation of the CCM.

Another opportunity of the developed database is that patients can be followed retrospectively over three years, which renders the study of more advanced indicators such as stepped-care indicators and clinical action oriented quality indicators possible enables on top of the classical, rather 'rough', quality indicators $[49,50]$. These advanced indicators look at the clinical path and require longitudinal data to also look at the actions (initiation and/or intensification of treatment) that are taken by healthcare providers (process) after certain outcome values (with regard to eGFR, $\mathrm{HbA1c}$, albuminuria and/or LDL-c) in the patient [54-57]. Until now, this has only been done in Belgium among diabetes patients treated with at least two insulin injections per day [51]. Research has shown the added value of these indicators, namely a better predictive value for hard health outcomes (such as micro and/or macro vascular complications) [51], as they depend less on patient characteristics.

The operationalization of this measurement framework of quality of care in a fragmented health data landscape as Belgium has revealed several problems and challenges. Due to the lack of a diabetes register and poor coordination between the primary, secondary and tertiary care level, quality of care research is often limited to datasets with full information of only one level of care and/or only covering one part of the patients (e.g. the most severe). For example, studies using EHR data [21,40] do often not fully capture specialist and inpatient care, and research [51] relying on data of hospitals (specialist and inpatient care) do not cover less severe patients, mainly treated at primary care level. Moreover, the majority of studies are only addressing one or two dimensions of care, because studying the three quality dimensions in a comprehensive way, requires different types of data (e.g. medication use and/or prescription data, health care use data, clinical data) and data at different levels (e.g. the organization, health provider and patient level), which are rarely included in one linked dataset. For example, quality of care research using health insurance data predominantly focusses on the process dimension, because of a lack of clinical information [52]. In studies relying only on EHRs, survey data, or health claims data organizational characteristics and the structure related quality indicators are rarely related to physician process and patients outcomes in studies [56], 
With this study we aim to provide solutions to these challenges. The unique and comprehensive multilevel dataset for the assessment and study of integrated T2D care has several strengths. As it consists of health insurance data, it includes in addition to basic sociodemographic information, extensive health care and medication data, cost information and professional information of the registered health care provider (e.g. financing system, organization type 'group vs. solo'). The data is longitudinal, exhaustive and very reliable, as the quality is not depending on the quality of the registration or reporting by the health care providers or patients. This because registration is routinely, standardized and necessary for reimbursement. One of the main limitations of health insurance data, namely the lack of clinical data, has been met in our dataset by the linkage with lab data. The linkage with self-collected primary care level data about the degree of implementation of the dimensions of the CCM makes this dataset very unique, including information about the three dimensions of quality of care. As a result, the data framework is adequate for quality assessment as well as for multilevel research to explain quality differences among patient groups and primary care organizations, through patient and GP-practice characteristics.

\section{Limitations and future research}

The main limitation of this project is to be found within its complexity. Linking the databases, which is a crucial step to measure the whole care continuum is complicated and requires much time and manpower. However, measuring quality is only helpful if actions can be taken and measurements can be repeated. If this is desired, the whole process needs to be redone from the start, inclusively the application at the different boards and the collection of the ACIC data. This study is therefore also a strong plea for linking lab and health insurance data and creating a routine diabetes register.

A comprehensive assessment of quality of care from a triple aim outcome perspective also includes patient experiences and cost of care [53]. Although the health insurance data provide the opportunity to make cost-effectiveness analyses, the analysis were beyond the scope of this paper. The patient perspectives of healthcare in first line are currently being developed and tested in a OECD project 'Patient-reported Indicator Surveys (PaRIS)' is ongoing $[54,55]$. The use of the PREM and PROM set was not yet possible in the current study.

\section{Conclusion}

The phased approach of the development of a theoretical framework of quality of care, and its translation in a data framework with measurable quality indicators, can be used as a template for the assessment of the quality of diabetes care in other countries with a complex data landscape and for other chronic diseases such as cardiovascular diseases, hypertension, COPD, etc..

The use of administrative health data and the linkage of different data sources is very enriching for quality of care research, but remains challenging and it requires a strong collaboration in different domains, such as expertise in the clinical field, statistics, epidemiology, and data management, as well as between academics and database administrators and privacy commission bodies.

\section{List Of Abbrevations}

T2D Type 2 Diabetes

HIS Health Information System

QI Quality Indicators

EHR Electronic Health Record

GP General Practitioner

FFS Fee-For-Service

CCM Chronic Care Model

ACIC Assessment of Chronic Illness Care tool

CoC Cascade of Care

IMA Intermutualistic Agency

HbA1c Hemoglobin A1c

TTP Trusted Third Party

CBSS Crossroads Bank for Social Security 
RN Random transport Number

VPN Virtual Private Network

eGFR estimated Glomerular Filtration Rate

LDL-c Low-Density Lipoproteincholesterol

OECD Organisation for Economic Co-operation and Development

PaRIS Patient-Reported Indicator Survey

PROM Patient-Reported Outcome Measure

PREM Patient-Reported Experience Measure

COPD Chronic obstructive pulmonary disease

\section{Declarations}

\section{Ethics approval and consent to participate}

The current study is approved by the Ethical Committee of the University Hospital Antwerp (ref.20/06/069) and all methods were performed in accordance with the relevant guidelines and regulations (Declarations of Helsinki).

Regarding the IMA and Lab data, is the controller exempt from the obligation to provide information to the persons whose data is processed, if the notification to the data subject proves impossible or involves a disproportionate effort; in particular in the case of processing for statistical purposes or for historical or scientific research or for population research with a view to protecting and promoting public health (cf. Article 9 of the law for the protection of privacy with regard to the processing of personal data). For the self-collected data at general practice level, an informed consent was always signed by the relevant general practitioner (and possibly other healthcare professional) of the practice.

\section{Consent for publication}

Not applicable

\section{Availability of data and materials}

Not applicable.

No dataset was used in this research article. All database administrators can be contacted freely

\section{Competing interests}

The authors declare that they have no competing interests

\section{Funding}

This project is funded by the Horizon2020 Framework Programme of the European Union, grant no 825432 . The study sponsor and funders were not and will not be involved in the study design; collection, management, analysis, and interpretation of data; writing of the report; and the decision to submit the report for publication.

\section{Authors' contributions}

Study concept and design: VB, KD, EW, RR, and JvO. Document review and expert consultations: VB and KD. Drafting of the manuscript: VB. Critical revision of the manuscript for important intellectual content: VB, KD, PB, EW, RR and JvO. Study supervision: EW and JvO. All authors read and approved the final manuscript.

\section{Acknowledgements}


We would like to kindly acknowledge the Intermutualistic Agency for sharing their expertise and providing guidance in the data application and linkage procedure. We also would like to extend our thanks to the consulted data experts for offering advice about the advantages and disadvantages of the existing data sources in Belgium.

\section{References}

1. World Health Organization. Global report on diabetes. World Health Organization. 2016. https://apps.who.int/iris/handle/10665/204871WHO Accessed March 23, 2021.

2. HIS-BELHES. Health Interview Survey - Belgian Health Examination Survey. Sciensano. 2018. https://www.sciensano.be/en/projects/healthexamination-survey Accessed March 23, 2021.

3. Kahn R, et al. Age at initiation and frequency of screening to detect type 2 diabetes: a cost-effectiveness analysis. Lancet. 2010;375(9723):13651374.

4. Gilson L, Doherty JE, Loewenson R, et al. Challenging inequity through health systems: Final Report Knowledge Network on Health Systems. Who commission on the social determinants of health. World Health Organization, Geneva, Switzerland, 2007.

http://www.who.int/social_determinants/resources/csdh_media/hskn_final_2007_en.pdf Accessed 22 february, 2021.

5. Grp TS. Health Systems, Patients Factors, and Quality of Care for Diabetes A synthesis of findings from the TRIAD Study. Diabetes Care. 2010;33(4):940-947.

6. Fokkens AS, Wiegersma PA, van der Meer K, et al. Structured diabetes care leads to differences in organization of care in general practices: the healthcare professional and patient perspective. Bmc Health Services Research. 2011;11(113). Doi: 10.1186/1472-6963-11-113

7. Donabedian A. The Quality of Care - How Can It Be Assessed. Jama-Journal of the American Medical Association. 1988;260(12):1743-1748.

8. Donabedian A. The Epidemiology of Quality. Inquiry-the Journal of Health Care Organization Provision and Financing. 1985;22(3):282-292.

9. Donabedian A. 20 Years of Research on the Quality of Medical-Care - 1964-1984. Evaluation \& the Health Professions. 1985;8(3):243-265.

10. Donabedian A. Quality, Cost, and Cost Containment. Nursing Outlook. 1984;32(3):142-145.

11. Vrijhoef HJM, et al. The nurse specialist as main care-provider for patients with type 2 diabetes in a primary care setting: effects on patient outcomes. International Journal of Nursing Studies. 2002;39(4):441-451.

12. Shojania KG, Ranji SR, Shaw LK, et al. Closing the Quality Gap: A Critical Analysis of Quality Improvement Strategies (Vol. 2: Diabetes Care). Rockville (MD): Agency for Healthcare Research and Quality (US). 2004 (Technical Reviews, No. 9.2.)

https://www.ncbi.nlm.nih.gov/books/NBK43938/ Accessed Februari 23, 2021.

13. Mahdavi M, et al. The relationship between context, structure, and processes with outcomes of 6 regional diabetes networks in Europe. Plos One. 2019;13(2):e0192599. Doi: 10.1371/journal.pone.0192599

14. Collins MM, et al. Quality of Life and Quality of Care in Patients With Diabetes Experiencing Different Models of Care. Diabetes Care. 2009;32(4):603-605.

15. Nocella JM, et al. Structure, process, and outcomes of care in a telemonitoring program for patients with type 2 diabetes. Patient Relat Outcome Meas. 2016;7:19-28.

16. Bak JCG, et al. National diabetes registries: do they make a difference? Acta Diabetol. 2021;58(3):267-278.

17. Peterson A, et al. Collaboratively Improving Diabetes Care in Sweden Using a National Quality Register: Successes and Challenges-A Case Study. Quality Management in Health Care. 2015;24(4):212-221.

18. Sigfrid LA, et al. Using the UK primary care Quality and Outcomes Framework to audit health care equity: preliminary data on diabetes management. Journal of Public Health.2006;28(3):221-225.

19. Jorgensen ME, et al. The Danish Adult Diabetes Registry. Clinical Epidemiology. 2016;8:429-434.

20. Gnavi R, et al. Determinants of Quality in Diabetes Care Process The population-based Torino Study. Diabetes Care. 2009;32(11):1986-1992.

21. Truyers $C$, et al. The Intego database: background, methods and basic results of a Flemish general practice-based continuous morbidity registration project. Bmc Medical Informatics and Decision Making. 2014;14(48) doi: 10.1186/1472-6947-14-48

22. Delvaux N, et al. Health Data for Research Through a Nationwide Privacy-Proof System in Belgium: Design and Implementation. Jmir Medical Informatics. 2018;6(4):219-228.

23. van Olmen J, et al. Scale-up integrated care for diabetes and hypertension in Cambodia, Slovenia and Belgium (SCUBY): a study design for a quasi-experimental multiple case study. Global Health Action. 2020;13(1). doi: 10.1080/16549716.2020.1824382.

24. Buffel V, Nicaise I. ESPN thematic report on inequalities in access to healthcare: Belgium. Europan Social Policy Network 2018 European Commission Brussels. 2019:1-21.

25. Goderis G, et al. Type 2 Diabetes in Primary Care in Belgium: Need for Structured Shared Care. Experimental and Clinical Endocrinology \& Diabetes. 2009;117(8):367-372.

26. RIZIV. The conditions for the integrated practice premium for general practice medicine. 2017. https://www.inami.fgov.be/nl/professionals/individuelezorgverleners/artsen/hulp/geintegreerde-praktijk/Paginas/toelichting-geïntegreerde-

Page 12/15 
praktijkpremie.aspx\#U_gebruikt_E-diensten_en_bereikt_de_drempel_voor_een_aantal_parameters. Accessed March 10, 2021.

27. Baptista DR, et al. The chronic care model for type 2 diabetes: a systematic review. Diabetology \& Metabolic Syndrome. 2016;8(7). Doi: 10.1186/s13098-015-0119-z

28. Stellefson M, Dipnarine K, Stopka C. The Chronic Care Model and Diabetes Management in US Primary Care Settings: A Systematic Review. Preventing Chronic Disease. 2013;10(e25). 10.5888/pcd10.120180

29. Bonomi AE, et al. Assessment of Chronic Illness Care (ACIC): A practical tool to measure quality improvement. Health Services Research. 2002;37(3):791-820.

30. Cramm JM, et al. Development and validation of a short version of the Assessment of Chronic Illness Care (ACIC) in Dutch Disease Management Programs. Health and Quality of Life Outcomes. 2011;9(49). Doi: 10.1186/1477-7525-9-49

31. Ali MK, et al. A Cascade of Care for Diabetes in the United States: Visualizing the Gaps. Annals of Internal Medicine. 2014;161(10):681-689.

32. Stokes A, et al. Prevalence and unmet need for diabetes care across the care continuum in a national sample of South African adults: Evidence from the SANHANES-1, 2011-2012. Plos One. 2017;12(10). Doi: 10.1371/journal.pone.0184264

33. Haber N, et al. Constructing the cascade of HIV care: methods for measurement. Current Opinion in Hiv and Aids. 2016;11(1):102-108.

34. Prenissl J, et al. Variation in health system performance for managing diabetes among states in India: a cross-sectional study of individuals aged 15 to 49 years. Bmc Medicine. 2019;17(1):92. Doi: 10.1186/s12916-019-1325-6

35. Price AJ, et al. Prevalence of obesity, hypertension, and diabetes, and cascade of care in sub-Saharan Africa: a cross-sectional, population-based study in rural and urban Malawi. Lancet Diabetes \& Endocrinology. 2018;6(3):208-222.

36. Danhieux K, et al. Waar haken mensen in de zorg voor diabetes en hypertensie af? Voorstelling van het SCale-Up diaBetes and hYpertensive care (SCUBY)-project. Huisarts Nu. 2020;49:213-215.

37. Vaes B, et al. Estimating the prevalence of diabetes mellitus and thyroid disorders using medication data in Flanders, Belgium. European Journal of Public Health. 2018;28(1):193-198.

38. Goosens $\mathrm{M}$, et al. De zorgtrajecten diabetes mellitus type 2 en chronische nierinsufficiëntie en kwaliteit van zorg: EVACQ Evaluation of Ambulatory Care Quality 2017-2019. Sciensano: Brussels, Belgium, 2019: D/2019/14.440/85.

39. Kiran T, et al. The Relationship between Primary Care Models and Processes of Diabetes Care in Ontario. Canadian Journal of Diabetes. 2014;38(3):172-178.

40. Van Casteren V, et al. Does the Belgian diabetes type 2 care trajectory improve quality of care for diabetes patients? Archives of Public Health. 2017;73(31). Doi: 10.1186/s13690-015-0080-1

41. Boutsen $\mathrm{M}$, et al. Vergelijking van kost en kwaliteit van twee financieringssystemen voor de eerstelijnszorg in België: een update. Intermutualistisch Agentschap - Agence Intermutualiste. 2017. https://ima-aim.be/IMG/pdf/maisons_medicales_ima-2.pdf Accessed Januari 22, 2021

42. KCE Reports 85A. Vergelijking van kost en kwaliteit van twee financieringssystemen voor de eerstelijnszorg in België. 2008. https://kce.fgov.be/report/85A Accessed Januari 30, 2021

43. Intermutualistisch Agentschap (IMA), Patiëntenbestanden en contacten van huisartsen: overzicht methodologie en lay-out resultaten, in PROJECT IMA-CHTA [IMA2011001]. 2018. https://www.ima-aim.be/IMG/pdf/methodologie_patientenbestand_huisartsen_externen-2021.pdf Accessed Januari 30, 2021

44. Van Casteren V, Bossuyt N, Moreels S, et al. De zorgtrajecten diabetes mellitus type 2 en chronische nierinsufficiëntie: impact op de kwaliteit van zorg, 2013. Brussel: Wetenschappelijk Instituut Volksgezondheid (WIV-ISP). Brussels, Belgium, 2013: D/2013/2505/24.

45. Sunaert P, Bastiaens $H$, Nobels F, et al. Effectiveness of the introduction of a Chronic Care Model-based program for type 2 diabetes in Belgium. Bmc Health Services Research. 2010;10(207). Doi: 10.1186/1472-6963-10-207

46. Claesen M, Gillard P, De Smet F, et al. Mortality in Individuals Treated With Glucose-Lowering Agents: A Large, Controlled Cohort Study. The Journal of Clinical Endocrinology \& Metabolism. 2016;101(2):461-469.

47. Maetens A, De Schreye R, Faes K,et al. Using linked administrative and disease-specific databases to study end-of-life care on a population level. Bmc Palliative Care, 2016;15(1):86. Doi: 10.1186/s12904-016-0159-7.

48. Yeoh EK, Wong MCS, Wong ELY, et al. Benefits and limitations of implementing Chronic Care Model (CCM) in primary care programs: A systematic review. International Journal of Cardiology. 2018;258:279-288.

49. Sidorenkov G, van Boven JFM, Hoekstra T, et al. HbA1c response after insulin initiation in patients with type 2 diabetes mellitus in real life practice: Identifying distinct subgroups. Diabetes Obesity \& Metabolism. 2018:20(8):1957-1964.

50. Sidorenkov G, Voorham J, de Zeeuw D, et al. Treatment quality indicators predict short-term outcomes in patients with diabetes: a prospective cohort study using the GIANTT database. Bmj Quality \& Safety. 2013;22(4):339-347.

51. Lavens A, Doggen K, Mathieu C, et al. Clinical action measures improve the reliability of feedback on quality of care in diabetes centres: a retrospective cohort study. Bmc Health Services Research. 2016;16(424): 10.1186/s12913-016-1670-5.

52. Tanaka H, Tomio J, Sugiyama T, Kobayashi Y. Process quality of diabetes care under favorable access to healthcare: a 2-year longitudinal study using claims data in Japan. Bmj Open Diabetes Research \& Care. 2016;4(1):e000291. DOI: 10.1136/bmjdrc-2016-000291

Page 13/15 
53. Hanefeld J, Powell-Jackson T, Balabanova D. Understanding and measuring quality of care: dealing with complexity. Bulletin of the World Health Organization. 2017;95(5):368-374.

54. OECD. Patient-reported Indicator Surveys (PaRIS). 2020. http://www.oecd.org/health/paris/ Accessed Februari 10, 2021.

55. Desomer A, et al. Het gebruik van patiëntuitkomsten en -ervaringen (PROMs/PREMs) voor klinische en beleidsdoeleinden. Health Services Research: KCE Reports 303A, 2018.

56. Devos C, Lefèvre M, Obyn C, et al. Performance of the Belgian health system - report 2019. Health Services Research (HSR) Brussels: Belgian Health Care Knowledge Centre (KCE), 2019. KCE Reports 313(D/2019/10.273/34).

\section{Figures}

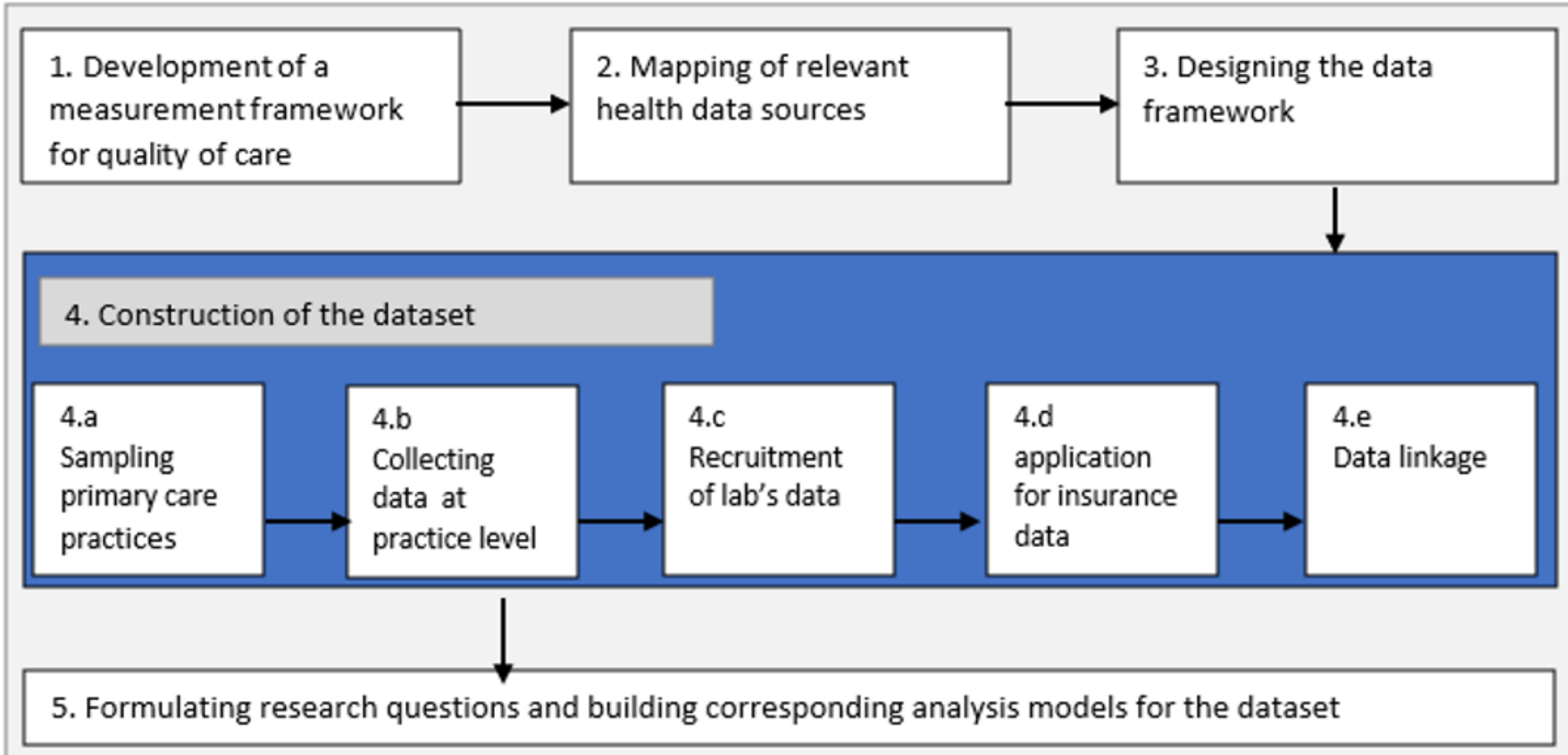

Figure 1

Flowchart of the phased approach of the development of the data framework and quality assessment tool

${ }^{1}$ multiple consultations rounds with epidemiologists, primary care providers, and research experts on diabetes and integrated care were necessary to define the framework and assess the comprehensive indicators list for relevance, validity and feasibility. 2,3 experts of the largest data sources were consulted: experts of the health insurance companies, the Intermutualistic agency, the Belgian Institute for Health (Sciensano), and the Intego network (Flemish general practice-based morbidity registration network). 


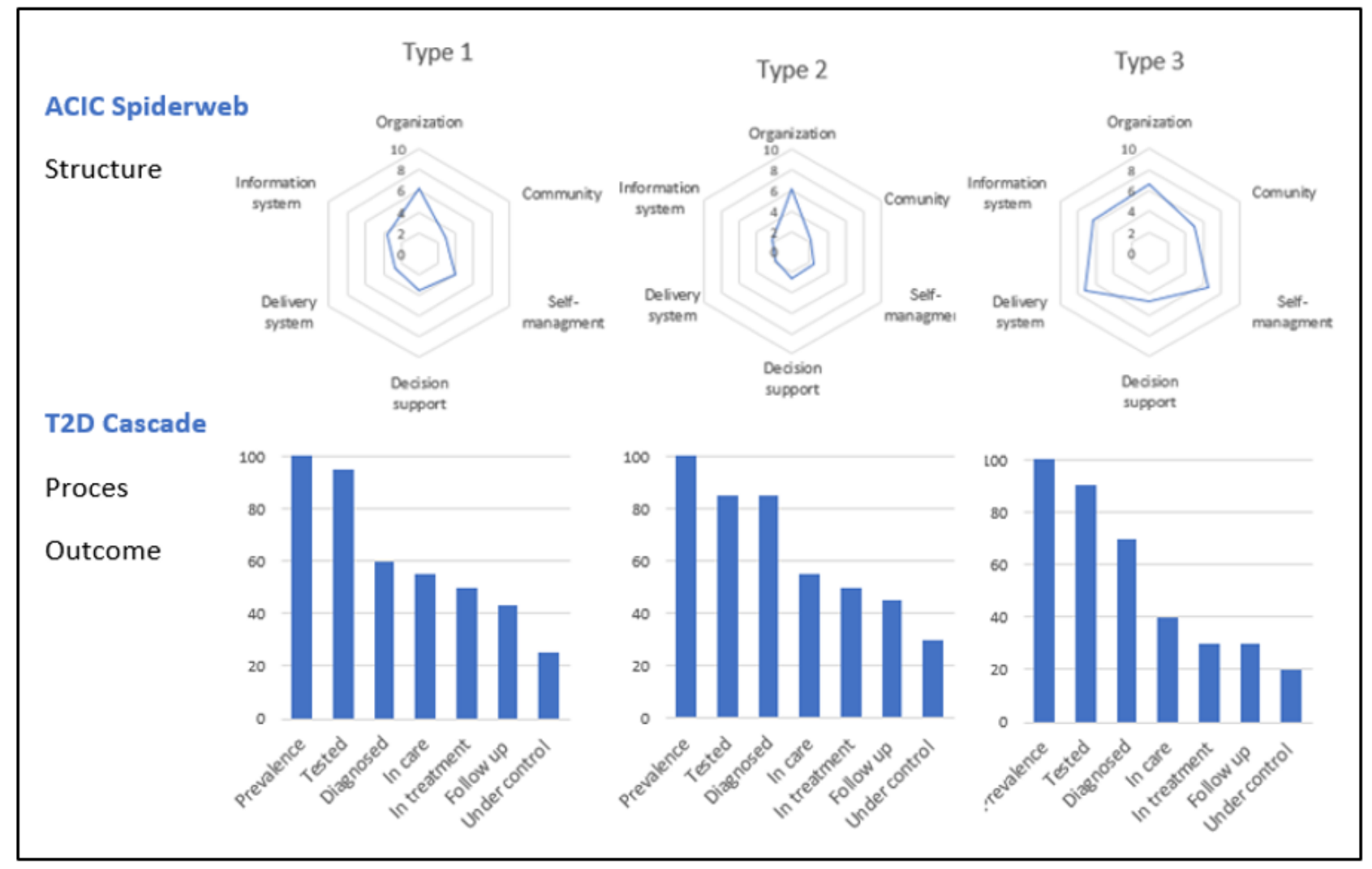

Figure 2

Fictive visualization of the quality indicators of integrated T2D care stratified by primary care practice type

\section{Supplementary Files}

This is a list of supplementary files associated with this preprint. Click to download.

- S1Box.docx

- S2Table.docx

- S3Flowchartandsteps.docx

- S4Figure.docx 